\title{
Research on Metonymy of Cognitive Linguistics from Corpus Approach of Computer Science
}

\author{
Ruifeng LUO \\ School of English Studies, Shanghai International Studies University,Shanghai, China \\ Foreign Languages Department, Sichuan Vocational and Technical College, Suining, Sichuan, China \\ Aocheng Garden of Hedong District, 629000 Suining City, Sichuan Province, China
}

\begin{abstract}
The rapid development of computer technology and corpus linguistics has realized the largescale corpus's collection, arrangement, annotation and processing. The corpus linguistics combines description with empirical analysis, and qualitative research with quantitative research that the various language phenomenons can be fully explained. The paper makes use of corpus-based approach to study Metonymy of Cognitive Linguistics and draws real data from Center for Chinese Linguistics Peking University of China (CCL), which makes the research more convincing.
\end{abstract}

\section{Introduction}

Corpus in linguistic research refers to the real language materials collected large-scalely and stored in computer with the aid of computer technology. These language materials can be retrieved after the annotation of some degree and applied to the description research and empirical research. Corpus Linguistics has undergone three stages according to the application of computer technology: raw corpora, modern corpus and contemporary corpus. The first one refers to the manual corpus before the appearance of computer, whose representatives are lexical indexing, lexicography, dialect research, language teaching research and grammar research. Its prominent characteristics is the manual collection of classical text corpora. Modern corpus contains the electronic corpus which large-scalely collect multi-text corpus of various forms by computer technology, and has three characteristics that are largescale real language material, are annotated and are easy to be retrieved. Contemporary corpus contains the COBUILD CORPUS, LANGMAN CORPUS, BRITISH NATIONAL CORPUS and META-COPORA which have larger capacity, cover wider and apply wider with more than one billion words.

In Chinese foreign language research, there are 10 representative key journals which show the interest the scholars concern much and reflect the latest academic research achievements. They are Foreign Language World, Foreign Language Teaching and Research, Chinese Translator's Journal, Technology Enhanced Foreign Language, Modern Foreign Language, Journal of Foreign Languages, Foreign Language Education, Applied Linguistics, Contemporary Linguistics and Shanghai Journal of Translation. The research of languages with Corpus-based approach can get more valid and real language materials rather than the artificial ones, which make the research more objective and convincing. This paper surveyed the numbers of articles with corpus approach in language key journals in recent 10 years. The histography shows that all the above journals have published corpus related articles. Technology Enhanced Foreign Language published 44 cor pus related papers, which ranked the first place. Foreign Language Education published 32 corpus related papers, which ranked the second place. Foreign Language Teaching and Research Foreign Language World, Journal of Foreign Languages and Modern Foreign Language published 18 corpus related papers, 12 corpus related papers, 10 corpus related papers, 9 corpus related papers corpus related papers respectively,which ranked the third, fourth, fifth place respectively. Applied Linguistics, Contemporary Linguistics and Shanghai Journal of Translation published 4 corpus related papers respectively, which ranked the bottom. 


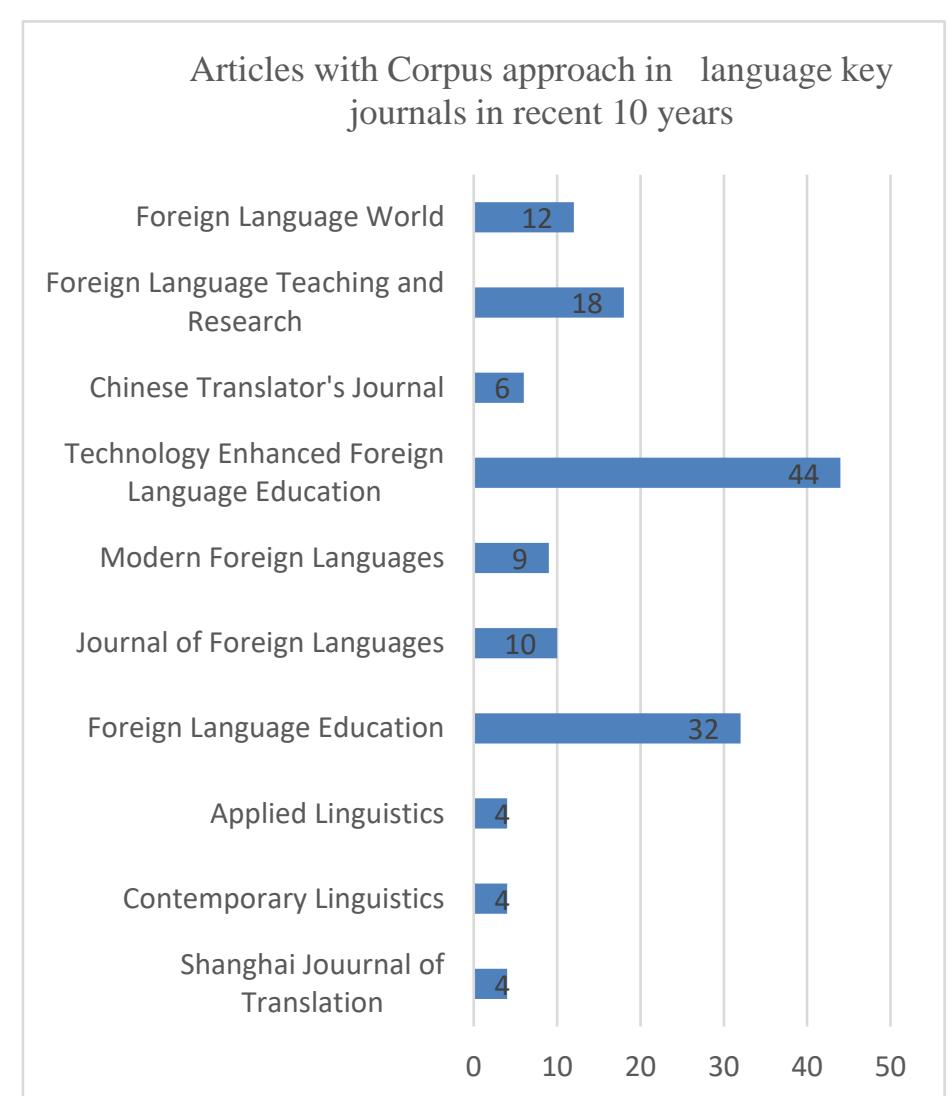

Fig 1. Numbers of articles with Corpus approach in language key journals from 2007-2017.

From ancient times on, Metonymy was regarded as one of the tropes. Its main function was substitution which means X Stands for Y. Aristotle classified it under metaphor. Traditional rhetoricians attempted to classify metonymies into types, not merely taking them into individual linguistic item. While the cognitive approach to metaphor is relatively recent development, the literature on metonymy has always taken what might be called a cognitive approach. Many attempts have been made to classify metonymies. Until 1980, Lakoff and Johnson wrote the book entitled Metaphor We Live By which pointed out that metonymy is a cognitive phenomenon and is not only one type of rhetorics. After Lakoff and Johnson's seminal work on the role of metaphor and metonymy in conceptualization, it has become increasingly apparent that metonymy may be even more fundamental than metaphor. Metonymy is a cognitive process in which one conceptual element or entity (thing, event, property), the vehicle, provides mental access to another conceptual entity (thing, event, property), the target, within the same frame, domain or idealized cognitive model (ICM). (Kovecses, 2006: 99). Radden and Kovecses (1999) suggested that the names given to types of metonymy by traditional rhetoricians are not unlike the terms given by the cognitive linguists now: "unlike metaphor, metonymy has always been described in conceptual, rather than purely linguistic term.In analyzing metonymic relations, traditional rhetoric operate with general conceptual notions such as CAUSE FOR EFFECT, CONTAINER FOR CONTENTS,etc. The difference is that cognitivists see these classes as mental categories which connect to other cognitive processes(and have the potential of being expressed multimodally), while more traditional approaches see them as classifications of linguistic items ocurring in speech and text and no more. And they made the taxonomy to metonymy and divide it into two main parts: Whole and part metonymies, Part and part metonymies. Whole and part metonymies comprise Thing and part ICM, Scale ICM, Constitution ICM, Event ICM and Category and property ICM. Part and part metonymies include Perception ICM, Causation ICM, Production ICM, Control ICM, Possession ICM, Containment ICM, Location ICM, Sign and reference ICM and Modification ICM.These taxonomies show the variety of metonymic relationships which exist and demostrate heterogeneous 'contiguity' is.

\section{Methods}

The study is based on the corpus of Center for Chinese Linguistics PKU (CCL), and shows the percentage of metonymical expressions in the target sentences. The corpus approach is divided into four steps. Firstly, we type in the intended Chinese characters in CLL and randomly extract 1000 sentences from the sentences containing the intended words. But when the total sentences containing intended words are few, we survey all of them. Secondly, we manually identify and pick out the sentences containing metonymy of intended words according to the principles of metonymy. Thirdly we analyze the linguistic patterns and get the percentage of the sentences containing metonymy. Lastly, we will list examples of sentences containing metonymy to make 
illustration. In Radden and Kovesces' version, they not only classified metonymy into two broad categories, but also employed specific ICM to support the central ideas which makes readers understand more clearly. So the paper combines Radden and Kovesces' $s$ model to analyze metonymy from corpus based approach and survey Category and property ICM.

\section{Results}

Category and property ICM means the salient property stands for the whole category. Lu Xun, Shakespeare, Du Kang, Zhu Geliang, Lei Feng, Newton and Einstein are well known persons and famous for their writings, delicious wine, clever mind, spirit of assisting others and contributions to scientific world. The proper names stands for their works or products, and attributes.

Table 1. "Category and property ICM" metonymy from CLL

\begin{tabular}{llll}
\hline $\begin{array}{l}\text { Lexical } \\
\text { items }\end{array}$ & $\begin{array}{l}\text { Numbers } \\
\text { surveyed } \\
\text { sentences }\end{array}$ & $\begin{array}{l}\text { of } \\
\text { Numbers } \\
\text { of } \\
\text { Metonym }\end{array}$ & Percentage \\
\hline Lu Xun & 1000 & 26 & $2.6 \%$ \\
$\begin{array}{l}\text { Shakes } \\
\text { peare }\end{array}$ & 1000 & 36 & $3.6 \%$ \\
Du & 181 & 32 & $17.67 \%$ \\
Kang & & & $8 \%$ \\
Zhu & 1000 & 80 & $10.8 \%$ \\
$\begin{array}{l}\text { Geliang } \\
\text { Lei }\end{array}$ & 1000 & 108 & $0.9 \%$ \\
Feng & & 9 & $2.7 \%$ \\
Newton & 1000 & 27 & \\
Einstei & 1000 & & \\
$\mathrm{n}$ & & & \\
\hline
\end{tabular}

\subsection{Proper names for works or products}

Lu Xun was the great writer translator and founder of the new literary movement in modern China. The books he wrote were broad and profound among which Diary of a madman, Kong Yiji, Medicine showed the performance of literary revolution, laying the foundation for the new literature, and the masterpiece Biography of Ah Q set up a monument for the new literary history, exerting impact on Chinese writers and writers of the world, and essays such as Hot air, Collection of Erxin were sharp, opening a new field of Chinese modern literature. His outstanding literary achievements not only enriched the cultural and artistic treasures of the Chinese nation, but also made contributions to world literature. He is one of the most accomplished writers in the world.Literally, Lu Xun refers to this great writer. Metonymically, Lu Xun refers to his works and the sentences of metonymic use are only 26 , accounting for $2.6 \%$ among randomly collected 1000 sentences. For example,

(1) Zhishifenzi you xihuandu Galgi, Lu Xun, du yiqie jiaojinbu zuopin de ren.

There are intellectuals who like to read Golgi, Lu Xun, and the more advanced works.
(2) Zai dule Jin Yong, Qiong Yao, Liang Shiqiuand, Lin Yutang zhihou, haijuede bugou xiaoqian de shihou, cai duiqi Lu Xun.

After reading Jin Yong, Qiong Yao, Liang Shiqiuand and Lin Yutang, I felt not enough to satisfy myself and began to read Lu Xun.

In the (1) and (2), Lu Xun don't refer to himself but metonymically refer to his works.

Shakespeare was outstanding dramatist and poet and writer in European Renaissance and the most outstanding writer of western literary history and the world. He occupied a special position in the history of European literature, and was regarded as "Zeus" in the Olympic Mountains of human literature. His tragic masterpieces were Hamlet, Othello, King Lear, Mac Beth, Romeo and Juliet and his comedies were A Midsummer Night' $s$ Dream, The Merchant of Venice and As you like it. Literally, Shakespeare refers to the great writer himself. Metonymically, Shakespeare refers to his works and the sentences of metonymic use are only 36, accounting for $3.6 \%$ among randomly collected 1000 sentences. For example,

(3) Ta lian shashibiya dou dubudong.

He can't even read Shakespeare.

(4) SunDayu Xiansheng shiyi fanyi shashibiya chumingde.

Mr Sun Dayu is famous for his translation of Shakespeare.

In the (3) and (4), Shakespeare don't refer to himself but metonymically refer to his works.

Du Kang, the fifth monarch of the Xia Dynasty of China, could brew good wine and was respected as "the ancestor of wine" in the ancient Chinese legend. Later generations use DuKang to refer to good wine. Literally, Du Kang refers to the man who can brew good wine. Metonymically, Du Kang refers to the wine and the sentences of metonymic use are only 32, accounting for $17.67 \%$ among the whole 181 sentences. For example,

(5) Heyi jieyou, weiyou dukang.

What can exclude my anxiety is the Du Kang.

(6) Jinnian yilai, tamen shengchande sanqiandun zhongguo dukang meifaxian yiping yin zhiliangwenti yaoqiu tuikuande.

This year, in three thousand tons of China Du Kang they produced, no bottle is returned because of the poor quality.

In the (5) and (6), Du Kang don't refer to the man himself but metonymically refer to the wine of high quality.

\subsection{Proper names for attributes}

Zhu Gelian, Shuhan prime minister of three Kingdoms of China, was a famous politician, strategist, calligrapher, essayist, inventor. Liu Bei invited him to be the official and he helped Liu to establish regime of Shu Han. He was the most important leader of Shuhan and had become the representative of loyal and wise man in traditional Chinese culture. Metonymically, ZhuGelian refers to Zhu Gelian' attributes of wisdom. For example, 
(7) Yiwei "shichangtong" geita chuge zhuyi, rangta pinqing mougongsi de xiaoshoudawang, chongdang tamenchang de "jingjiZhu Geliang".

A man who knows the market well gave him an idea and asked him to hire a company's sales king, as their factory's economic "Zhu Geliang".

(8) Nalide dangiaren yuan chugaojia qing Zhu Geliang, yong wuzhi youdai wailai de rencai.

The man in charge there is willing to pay a high price to employ "Zhu Geliang", to attract talents.

In the (7), Zhu Geliang doesn't refer to himself but metonymically refer to the man who are very wise and specialized in the economy field. And in the (8), Zhu Geliang metonymically refers to any wise talent who can serve the institution.

Lei Feng, from Hunan Province of China, helped countless people in his short life and served people with heart and soul, who was the soldier of the Chinese people's Liberation Army, the great Communist fighter and died in his twenty second years old. Because Lei Feng was willing to help others, his name in the mainland of China has become representative of "man with good spirit of offering help to others without getting reward". Lei Feng's faith, great love and selfless spirit is the best portrayal of the spirit of the Chinese nation. "Lei Feng spirit" inspired generation after generation. Literally, Lei Feng refers to this great man who helped others a lot wholeheartedly. Metonymically, Lei Feng refers to his spirit and the sentences of metonymic use are only 108, accounting for $10.8 \%$ among randomly collected 1000 sentences. For example,

(9) Youyu shangpindachao de chongji, xueleifeng, zuohaoshi, zai yixieren de xinmuzhong sihu bu name shimaole.

Due to the impact of the commodity tide, learning from Lei Feng to do good things, in the eyes of some people, seem to become less fashionable.

(10) Laoren binfengshang sheshenjiuren de gushi, shi qianbaiwan guanzhong gandongzhiyu fasheng kunhuo, zhongyu yinfa yichang "xifang shifou yeyou Lei Feng" de taolun.

That the old man sacrificed himself to save others in the snow-capped mountain peak moved millions of the audience and triggered a confusion whether there is Lei Feng in the West.

In the (9) and (10), Lei Feng doesn't refer to Lei Feng himself but metonymically refer to the man with lofty spirit who is willing to help others without getting any reward.

Newton was the president of the Royal Society and the famous British physicist, who described universal gravitation and the three laws of motion. These descriptions established the scientific view of the physical world for the next three centuries and became the foundation of modern engineering. Through the consistency proof of Kepler's laws of planetary motion and his theory of gravity, he proved that the ground object and the motion of celestial bodies all followed the same laws of nature and provided a strong theoretical support for the center of the sun, and to promote the scientific revolution. So he made great contribution to human's science. Literally, Newton refers to Newton himself who made great contribution to human's science. Metonymically, Newton refers to anyone who contributes to the science and the sentences of metonymic use are only 9 , accounting for $0.9 \%$ among randomly collected 1000 sentences.

Einstein, a Jewish physicist, put forward the photon hypothesis, successfully explained the photoelectric effect, won the Nobel prize in physics, and founded the theory of relativity. He had laid a theoretical foundation for the development of nuclear energy in the modern science and technology and his profound influence and wide application opened up a new era of modern science. He was recognized the greatest physicist as the Galileo and Newton. Literally, Newton refers to Einstein himself who made great contribution to human's science. Metonymically, Einstein refers to anyone who contributes to the science and the sentences of metonymic use are only 27 , accounting for $2.7 \%$ among randomly collected 1000 sentences. For example,

(11) Renlei buyinggai zhiyou yige niudun, yige aiyinsitan, yinggai you shige, baige Niudun, Aiyinsitan.

Human beings should not only have a Newton and a Einstein. There should be tens and hundreds of Newtons and Einsteins.

(12) Zhonghuaminzu yiding huizai buyuandejianglai wei renlei gongxian yige Niudun huo Aiyinsitan.

The Chinese nation will certainly contribute a Newton or Einsteiton to the world in the near future.

In the (11) and (12), Newton and Einsteiton don't refer to themselves but metonymically refer to the men who are very creative and make great contribution to the scientific world.

\section{CONCLUSION}

The paper carries out a corpus-based study of "Category and property ICM" metonymy. It is found that surveyed names such as Lu Xun, Shakespe are metonymically refer to the works they had written. And Du Kang metonymically refer to the good wine he made. Zhu Gelian metonymicaly refers to his attributes of wisdom to plan events successfully and Lei Feng metonymically refers to his spirit to help others without getting any reward. Newton and Einstein metonymically refer to anyone who makes contribution to science. In "Proper Names for Works or Products, and Attributes" metonymy according to CLL, the percentages of Du Kang and Lei Feng.are highest, accounting for $17.67 \%$ and $10.8 \%$ respectively. The percentages of Newton and Lu Xun are the lowest, accounting for $0.9 \%$ and $2.6 \%$ respectively. The percentages Shakespeare and Einstein are intermediate, accounting for $3.6 \%$ and $2.7 \%$ respectively.

\section{ACKNOWLEDGMENTS}

This research was financially supported by the Fund of Education Department of Sichuan Province, China (Grant NO.15SB0255 \& Grant NO.16SB0293), by Internationalization Project of Sichuan Vocational and Techincal College and by the Fund of Teaching and 
Reforming project of Sichuan Vocational and Techincal College.

Ruifeng LUO is $\mathrm{PhD}$ candidate of Shanghai International Studies University and lecturer of Sichuan Vocational and Technical College of China, whose research interest is Cognitive Linguistics.

\section{REFERENCES}

1. Bowman, Gibbs, R. The Poetics of Mind: Figurative Thought, Language, and Understanding. Cambridge: Cambridge University Press (1994).

2. Gibbs,R. Speaking and thinking with metonymy. In K-U.Panther and G.Radden (eds). Metonymy in Language and Thought. Amsterdam: John Benjamins (1999).

3. Lakoff, Gand Johnson, M. Metaphor We live by. University of Chicago Press (1980/2003).

4. Littlemore, J Metonymy. Cambridge University Press (2015).

5. Kovecses, Z. Language, Mind and Cultur: A Practical Introduction. Oxford University Press (2006).

6. Radden, G., and Kovecses, Z. Towards a theory of metonymy. In K-U.Panther and G.Radden (eds.). Metonymy in Language and Thought. Amsterdam: John Benjamins (1999).

7. Radden, G., Kopche, K.-M., T., and Siemund, P. The construction of meaning in language. In G.Radden, K.-M.. Kopche, T. Berg and P. Siemund (eds.). Aspect of Meaning Construction. Amsterdam: John Benjamins, 1-15 (2007).

8. Wang, Kefei. Tentative Research on Corpus Translatology. Shanghai: Shanghai Jiaotong University Press (2012). 